\title{
A Solution for Android Device Misplacement through Bluetooth-enabled Technology
}

\author{
Kaven Raj S/O Manoharan \\ Multimedia University/Faculty of Information Science \& Technology, Melaka, Malaysia \\ E-mail: 1112701704@student.mmu.edu.my \\ Siew-Chin Chong* \\ Multimedia University/Faculty of Information Science \& Technology, Melaka, Malaysia \\ E-mail: chong.siew.chin@mmu.edu.my \\ Kuok-Kwee Wee \\ Multimedia University/Faculty of Information Science \& Technology, Melaka, Malaysia \\ E-mail: wee.kuok.kwee@mmu.edu.my
}

\begin{abstract}
The number of smartphone users and mobile application offerings are growing rapidly nowadays. A mobile device is currently considered as the most powerful and most needed device of this modern century. Every day new mobile applications are developed with their own compatibility, making sure to serve correctly to a particular smartphone model and its specifications. The goal of this project is to develop a self-help Android application namely "Dont Forget Me", which is user friendly and well defined to solve the problem of misplaced or lost smartphone devices. This missing phone prevention alert application practically pairs with another device using Bluetooth connection. The Bluetooth connection is established in order to prevent the user from forgetting to bring along the device or being stolen by someone. If the Bluetooth connection between the paired devices is disconnected hence an alarm and message notification are triggered to notify the user that the device was not brought along with them. A website application is also developed purposely in serving the user to track, locate and lock the missing device.
\end{abstract}

Index Terms-Android, Alarm, Bluetooth, GPS, SMS, Missing.

\section{INTRODUCTION}

The growth of technology in mobile devices nowadays has increased radically, especially the applications in smartphones. Compared to the cellular phones, smartphones provide better facilities and conveniences. Users often expect smartphone can be functioned as a personal computer. Recently, smartphones which are running on an operating system either iOS or Android are dominated the mobile phones market sales [1]. Besides that by 2018, more than 90 percent of Bluetooth enabled smartphones are expected to be Smart Ready devices [2]. The Global Positioning System (GPS) is a satellite-based navigation system made up of a network of 24 satellites placed into orbit by the U.S. Department of Defense. GPS was originally intended for military applications, but in the 1980s, the government made the system available for civilian use. GPS works in any weather conditions, anywhere in the world, 24 hours a day. There is no subscription fee or setup charges to use GPS [3].

The possibilities of a person to lose or misplaced their smartphone are very high if precaution steps are not taken efficiently. There are plenty of ways that can be taken to prevent users from misplacing their smartphones. One of them is by using an application that locates your misplaced or lost smartphone. These applications use satellite and internet connection to track down the smartphone remotely.

However, those available applications only help the user to track and locate the already misplaced or lost smartphones. Thus, it is better to prevent the user from forgetting to bring along their smartphone at the first place rather than taking action after losing it. The main objective of the proposed app "Dont Forget Me" is to alert the users at the first place so that the users will always remember to bring along their smartphones before the devices are misplaced. Even if the device is missing, the proposed app is able to notify the users through SMS and to track the GPS location of the device, as well as to lock the device remotely.

The project is beneficial in the following scenarios:

- $\quad$ Short Message Service (SMS) Notification using SmsManger Android library. This function enables user to enter the desired third person phone number and the message that need to be sent. Later once the project application detects a disconnected Bluetooth connection, this application automatically sends the SMS to the desired third person notifying them about the misplaced device.

- Alarm Notification using MediaPlayer Android library. This function is triggered when the application detects a disconnected Bluetooth 
connection. User will be notified by a loud preset ringtone in the application, this will be then disabled once the user retrieves the misplaced device.

- Locating and Tracking, this function is enable thanks to the open source Open Device Manager (ODM) created by a famous mobile software development community known as XDA Developers. User needs to register their device first and then track their lost device using the website set up in this project. Besides that, the ODM enables the user to remotely lock the misplaced device with password in order secure the device from breaching by thief.

The rest of the paper is organized as follows. In Section II, some of the related Android applications are briefly reviewed. The proposed system design is discussed in Section III. In Section IV, the implementation process of the proposed system is explained. The testing scenario and result are reported in Section V and finally, the conclusion is given in Section VI.

\section{RELATED WORK}

Every Android developer wants to design or innovate a unique application that may improve and influence the daily activities of human life. There have been lots of competitors in the Android Development market. But since Android is an open source operating system, it has given chance to Android developers to enhance their existing work as well to create what is currently topping in the market demand. According to Sundar Pichai, Android's Senior Vice President, he stated that Android now has over 1 billion active users and is still the dominant mobile platform [4].

As regards to this project's aim, there have been plenty of existing works which were developed to track the location of the smart devices. However, most of them only serve the purpose of finding the missing phone after the device is lost. Here are some of the current wellknown related Android applications and also Mac iOS applications with a brief outline of their specifications.

a. Plan B [5]: This Android application developed by Lookout Mobile Security uses the GPS to locate the misplaced or lost phone. This application will send an email to the Gmail account of the misplaced or lost phone location. User can relocate the lost phone by texting "locate" to the phone number and the latest location is again sent to the Gmail account.

b. AntiDroidTheft [6]: This Android application developed by Zobo Technologies is able to track lost or misplaced smartphone. This application also allows the user to track down the activity of their family members by using GPS. User needs to create an account in this application and provide the email and password for the app. Once it is approved, user can locate each other phone with just a push of a button.

c. GadgetTrak [7]: This iOS application is developed by WestinTech which allows users to find and protect the information in your device. It tracks the device on a map and remotely locks it so that theft would not be able to steal the valuable information in the device. If the device is nearby it would play a sound to notify the location of the device. User is able to display message showing to whom to contact in order to retrieve the missing device.

d. FoneHome [8]: This iOS application developed by Appmosys LLC allows user to remotely track your device location as it moves. In case a theft has stolen the device, it takes the picture of the theft and the picture can be viewed remotely by the user GPS is enabled and a loud siren is activated for device searching.

Table 1. Comparison table of the existing and the proposed applications.

\begin{tabular}{|c|c|c|c|c|c|}
\hline Features & 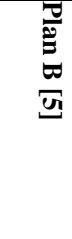 & 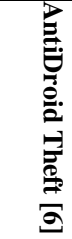 & 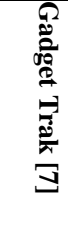 & 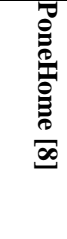 & 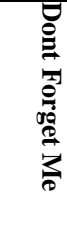 \\
\hline $\begin{array}{l}\text { Bluetooth } \\
\text { Capability }\end{array}$ & No & No & No & No & Yes \\
\hline $\begin{array}{c}\text { Security } \\
\text { Password }\end{array}$ & No & No & No & No & Yes \\
\hline $\begin{array}{c}\text { Navigation } \\
\text { Accuracy }\end{array}$ & No & No & No & No & Yes \\
\hline GPS Tracking & Yes & Yes & Yes & Yes & Yes \\
\hline $\begin{array}{c}\text { Alarm } \\
\text { Notification }\end{array}$ & No & No & No & No & Yes \\
\hline $\begin{array}{c}\text { SMS } \\
\text { Notification }\end{array}$ & No & No & No & No & Yes \\
\hline OS & $\begin{array}{c}\text { Andr } \\
\text { oid }\end{array}$ & $\begin{array}{c}\text { Andr } \\
\text { oid }\end{array}$ & $\mathrm{iOS}$ & $\mathrm{iOS}$ & $\begin{array}{c}\text { Andr } \\
\text { oid }\end{array}$ \\
\hline
\end{tabular}

Table 1 shows the comparisons between the mentioned existing apps and the proposed app. Among the apps, the Plan B [5] application seems to be the best followed by AntiDroid Theft [6], PoneHome [8] and finally Gadget Trak [7]. There are also other tracker apps available in the market such as GPS Phone Tracker Pro [10], Find My Android Phone! [11], Where's My Droid [12], SeekDroid [13] and others. Since Android platform has made easy for the developers to create a fully functional application so the scope of this project is limited to Android devices only.

\section{PROPOSED SySTEM DESIGN}

The main aim of this project is to develop an Android application that will trigger an alarm to notify the smartphone users in a case where they forget to bring along their smartphone and to improve on the existing application features such as debugging, security and also introduce some new features. The system architecture is shown in the Fig. 1 below. 


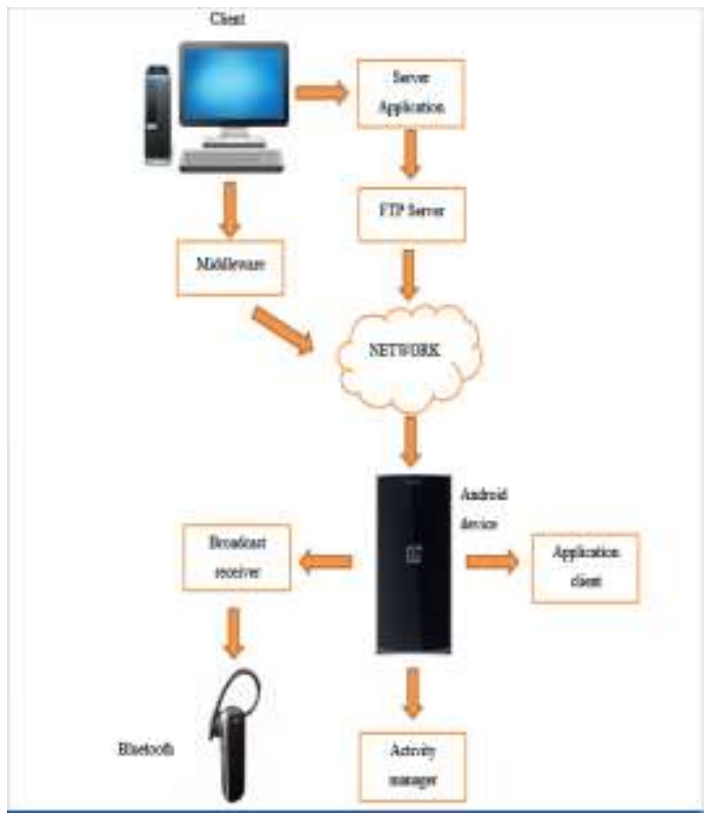

Fig.1. System Architecture

This section presents two important factors of the prototype: the client and server applications. Furthermore, the major components for this proposed application and some of the important algorithms are elaborated.

\section{A. The Client and Server Application}

Fig. 2 shows the client and server application flow diagram. If the user chooses to pair Bluetooth, the left option of the flow should be followed which is the client side of the application. Here user is able to pair, unpair, connect and disconnect to a particular Bluetooth device. The prototype will trigger the alarm notification and also send SMS to a third person if the Bluetooth connection is disconnected. The third person could be any of the user's family members, friends or others.

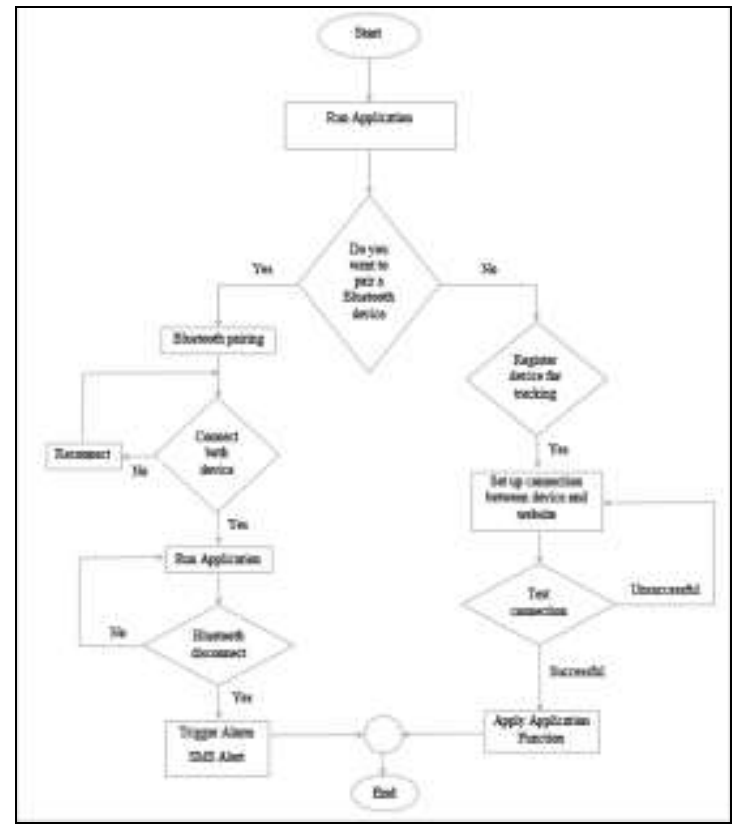

Fig.2. The Client and Server Application Flow Diagram
User will be directed to the server side application of the system if the user chooses to search for the misplaced or missing device. Here the user is able to remotely track and lock the smartphone with a password to fail any attempt of the theft to breach the important information in the device.

\section{B. Application Scenarios}

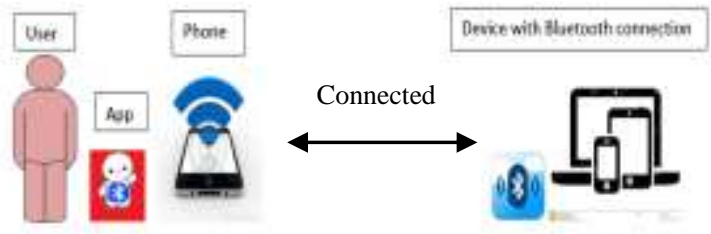

Fig.3. Making connection with other Bluetooth devices

Fig. 3 shows a scenario when a user has the phone installed with this proposed application named "Dont Forget Me" and tries to connect to another device with Bluetooth connection enabled. The Dont Forget Me app allows user to enable and make Bluetooth connection.

Once the app is activated, it will always listen for any incoming connection request from the Bluetooth devices nearby. The Bluetooth request is then accepted and a Bluetooth connection is established between both devices. The app will also check for any chances in the Bluetooth connection range and will try to reconnect if the distance of the devices goes out of range.

Fig. 4 shows the scene where a connection is lost between the phone and the other Bluetooth device. In this case, the Dont Forget Me app will automatically trigger the alarm alert and the SMS alert function.

This Alarm alert function works by using the default alarm tone set by the user and will ring continuously until the user acquires back the misplaced phone. The Alarm alert will also trigger although the phone is in silent mode or in vibrate mode.

Next is the SMS alert function which works with the desired third person phone number being saved into the application. The SMS function will be triggered after the Bluetooth connection is lost (when the distance of the two devices are out of range). The application will send a text message containing the details required for login in the ODM [9] and tracking down or locking the phone remotely.

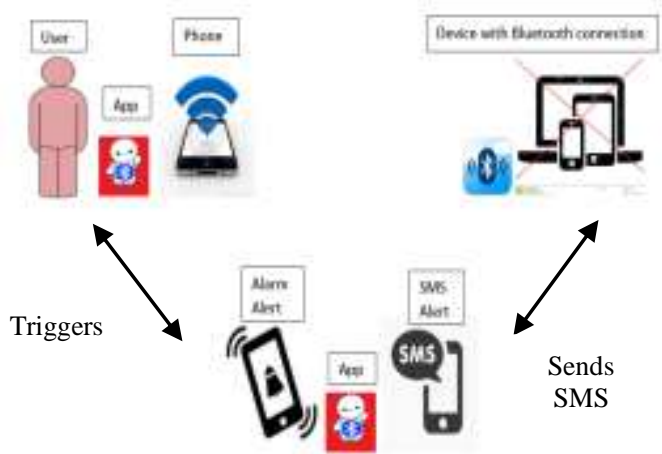

Fig.4. Action taken by the app if Bluetooth is disconnected 


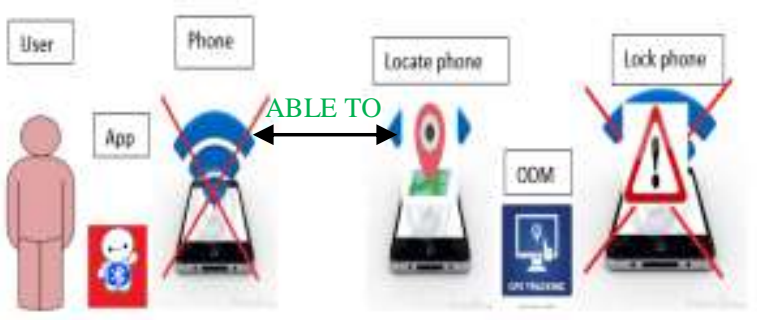

Fig.5. Locating and securing the phone remotely using ODM

Scenario in Fig. 5 shows when the phone goes missing or is stolen by thief. In this case, the ODM comes to the play. This ODM is an open source application whereby user can access the website to locate the missing phone and also remotely securing the phone with a password.

User is required to register the device with the ODM at the first place and enable the GPS function for tracking purpose if the phone goes missing later. This ODM app gives the exact coordinate of the missing phone and from there user is able to trace down the location of the phone.

ODM also has a function whereby the user can remotely lock the phone with any password from the user. This function is useful so that in cases where a thief wants to access important information in the device, the password from the user is needed in order to access the phone.

\section{Important Source Codes from Client Application}

In this section the codes for each major activity in the client-side application will be shown. All the source codes are in Java programming language and are run by Eclipse.
a. Alarm Alert Activity
b. SMS Alert Activity;
c. Device Tracking Activity.

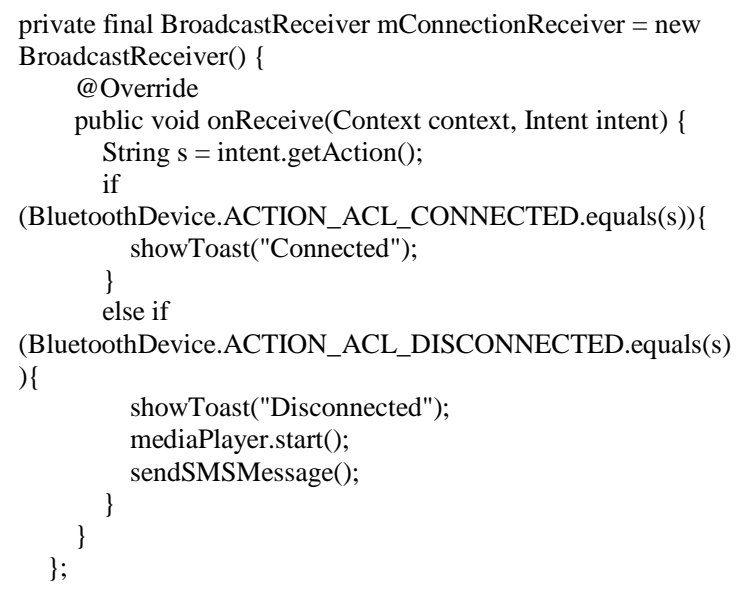

Fig.6. Alarm Alert Activity

Fig. 6 shows the code for implementing MediaPlayer. The system uses MediaPlayer to trigger alarm if there is disconnection in the Bluetooth function. The system will use the default ringtone and the mediaPlayer.start() will trigger the ringtone set. Once the user retrieves the misplace phone, the user is able to disable the alarm triggered.

Fig. 7 shows the code for implementing SMS Alert. The system uses the SmsManager that manages SMS operation to send messages to a mobile device. In this system, users are allowed to send SMS to a third person whereby in a case of the user had mistakenly misplaced their device, the application will automatically send the message to the desired third person mobile device notifying that the user has misplaced the phone and ask them to find their misplaced phone.

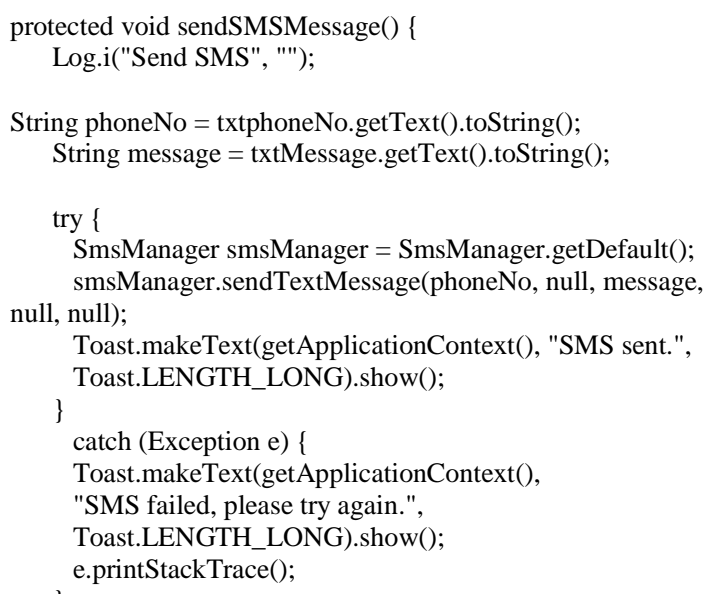

Fig.7. SMS Alert Activity

The code will trigger the SMS Notification when Bluetooth connection is disconnected. The application will accept both phone number string and text message

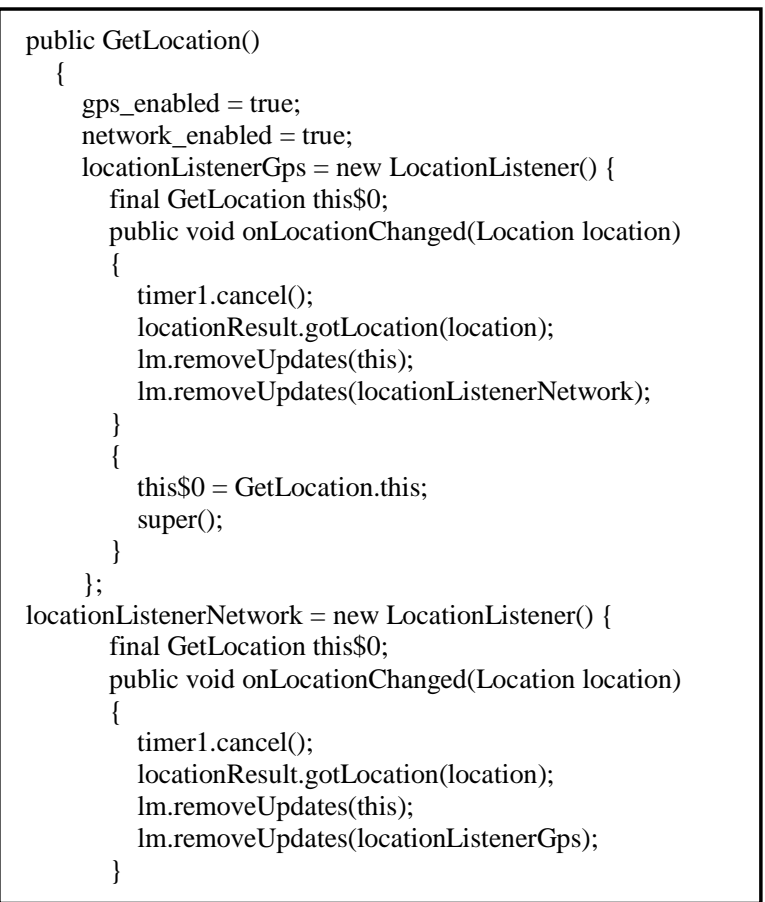

Fig.8. Device Tracking Activity 
string from the user and then call that string into the function and sent it to the third person.

In this Fig. 8, the system uses LocationManager and LocationListener to get the latest location of the missing phone. Users first need to register and login to a website that is set up for Locating and Tracking purposes. After that users are able to track down to secure their device from remote areas. This function is extracted from an open source ODM.

\section{IMPLEMENTATION PROCESS}

\section{A. Prototype Functionalities}

This application practically pairs with another device using Bluetooth connection. This Bluetooth connection is established in order to prevent the user from forgetting to bring along the device. If the Bluetooth connection between the paired devices is disconnected hence an alarm is triggered to notify the user that the device was not brought along with them. Besides that the SMS Notification will also be triggered to send the saved text message to the desired third person number. User will also be allowed to track and locate the missing device via the ODM website.

There are three major functions that can be performed by the installed client-side application on the device. They are;

a. Device Bluetooth Pairing and Unpairing Activity.

b. Device Enable and Disable Bluetooth Connection Activity.

c. SMS Notification Activity.

And on the server-side application which will be installed on the computer. There are three major functions.

a. User has to surf the website on his/her computer.

b. Locating and Tracking the misplaced phone.

c. Remotely securing the phone with password.

\section{B. Prototype Graphical User Interface}

a. Device Bluetooth Pairing and Unpairing Activity

b. Device Enable and Disable Bluetooth Connection Activity

c. SMS Notification Activity

d. Locating, Tracking and Securing the Device.

Fig. 9 shows device Bluetooth Paring and Unpairing Activity. The application will list out all the available Bluetooth devices within the range to the user's device. Here the user is able to pair and unpair with the desire Bluetooth device in range.

Fig. 10 shows device enable and disable Bluetooth Connection Activity. Once the user has enabled the Bluetooth, there will be a text saying "Bluetooth is On" on the top of the screen. By clicking the Disable" button, the Bluetooth will be turned off.

Fig. 11 shows SMS notification activity. User is able to enter the desired third person's phone number and the text message so that when the user misplaced the device, this application will auto send SMS to the third person.
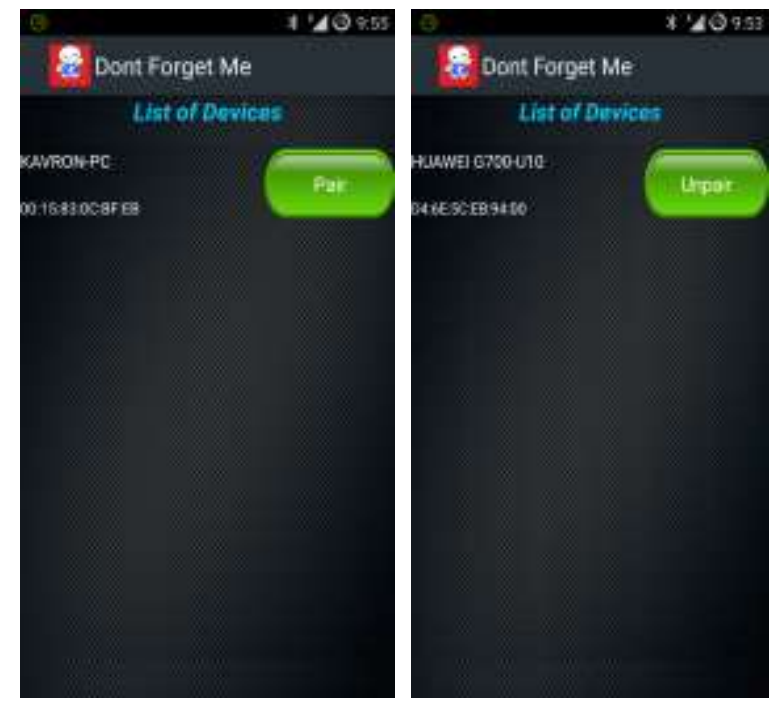

Fig.9. Device Bluetooth Pairing and Unpairing Activity

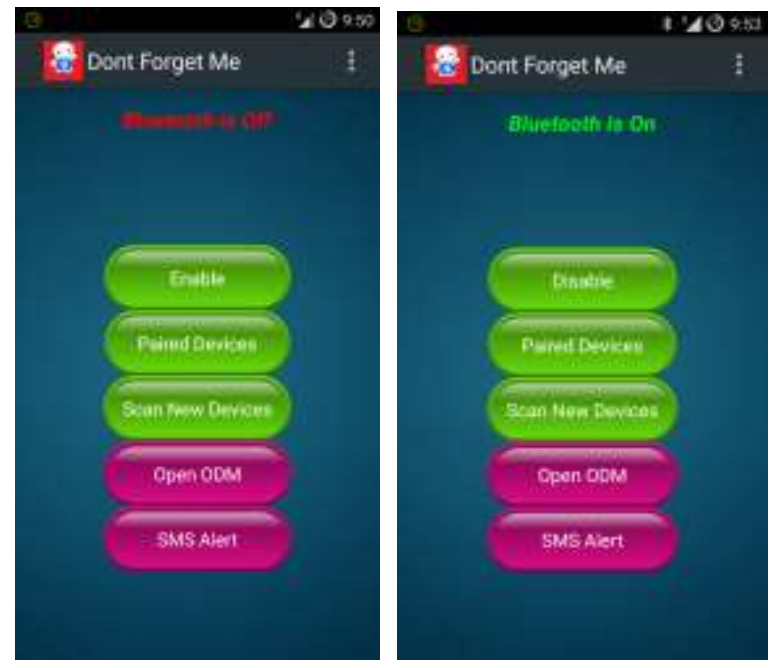

Fig.10. Device Enable and Disable Bluetooth Connection Activity

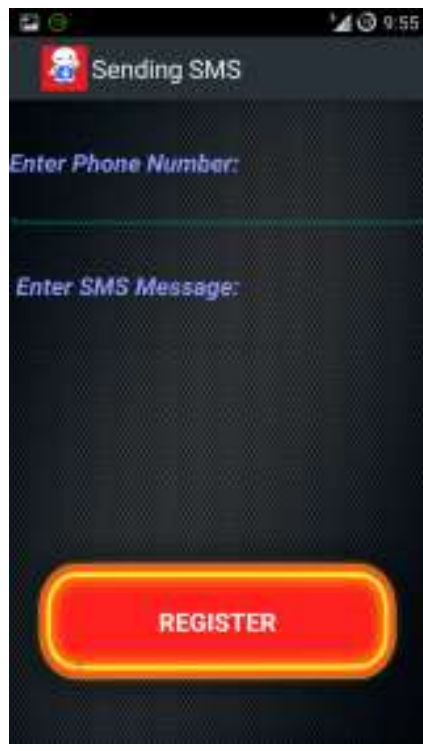

Fig.11. SMS Notification Activity 
Fig. 12 shows the screen of locating, tracking and also securing the device remotely by using Open Device Manager (ODM). User is able to get latitude and longitude coordinate of the missing device for tracking purposes. User is also able to lock the device remotely with a new password in order to safely secure the phone information from being stolen.

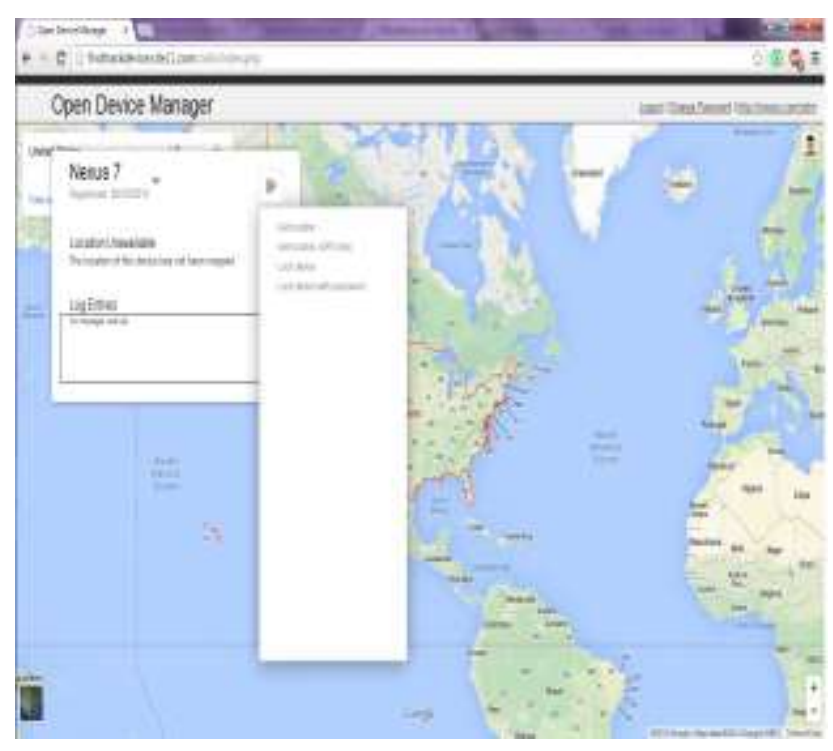

Fig.12. Locating, Tracking and Securing the Device

\section{RESULT}

Several software testing are conducted to test the validity and reliability of the application. Unit test is performed on individual module to evaluate whether they fits the intended purpose. After the individual modules pass the unit test, the individual modules are combined and integration test is carried out to verify the functions, performance and reliability of the application. The test cases are presented in Table 2.

On the other hand, a survey has been conducted to collect the feedback from the public towards the usefulness and efficiency of the proposed app. This survey has received responses from 83 potential users. Most of the participants own an Android device, either smartphone or tablet. $93 \%$ of them have experience in downloading Android apps frequently which reflects that the Android apps are getting popular among the smart device users.

In this survey, $89 \%$ of them feel comfortable with the proposed idea and $80 \%$ of participants have the interest to install the proposed apps in their device. $75 \%$ of the participants are satisfied with the overall performance of the application. Besides, $34 \%$ of the users would like to be updated with the advancement of the project.
Table 2. Test Cases

\begin{tabular}{|c|c|c|}
\hline Test Case & Expected Output & Result \\
\hline Turn On Bluetooth & Bluetooth enabled & Pass \\
\hline Turn Off Bluetooth & Bluetooth disabled & Pass \\
\hline Scan For New Device & Found new devices & Pass \\
\hline $\begin{array}{llll}\text { Unable } & \text { To } & \text { Find } & \text { New } \\
\text { Device } & & & \end{array}$ & No Device is listed & Pass \\
\hline Pairing New Device & $\begin{array}{l}\text { Device is paired } \\
\text { successfully }\end{array}$ & Pass \\
\hline $\begin{array}{llll}\text { Unable } & \text { To } & \text { Pair } & \text { New } \\
\text { Device } & & & \end{array}$ & Pairing failed & Pass \\
\hline $\begin{array}{l}\text { Unpairing With Paired } \\
\text { Device }\end{array}$ & Devices are unpaired & Pass \\
\hline $\begin{array}{lcc}\text { Unable } & \text { To } & \text { Unpairing } \\
\text { Paired Device } & \end{array}$ & $\begin{array}{l}\text { Device are failed to } \\
\text { unpair }\end{array}$ & Pass \\
\hline Connect To Device & Device is connected & Pass \\
\hline $\begin{array}{l}\text { Unable To Connect To } \\
\text { Device }\end{array}$ & Device is not connected & Pass \\
\hline Disconnecting To Device & Device is disconnected & Pass \\
\hline $\begin{array}{ll}\text { Unable To } & \text { Disconnect } \\
\text { With Device } & \\
\end{array}$ & $\begin{array}{l}\text { Device is not } \\
\text { disconnected }\end{array}$ & Pass \\
\hline $\begin{array}{l}\text { Register SMS Number } \\
\text { and Message }\end{array}$ & $\begin{array}{l}\text { Third party's SMS } \\
\text { number and message are } \\
\text { registered }\end{array}$ & Pass \\
\hline $\begin{array}{l}\text { Unable To Register SMS } \\
\text { Number and Message }\end{array}$ & $\begin{array}{lrr}\text { SMS } & \text { number } & \text { and } \\
\text { message } & \text { are } & \text { not } \\
\text { registered } & & \\
\end{array}$ & Pass \\
\hline $\begin{array}{lll}\begin{array}{l}\text { Entering } \\
\text { Message }\end{array} & \text { User } & \text { SMS } \\
\end{array}$ & SMS Message is saved & Pass \\
\hline $\begin{array}{l}\text { Unable to Enter User } \\
\text { SMS Message }\end{array}$ & $\begin{array}{l}\text { SMS Message is not } \\
\text { saved }\end{array}$ & Pass \\
\hline $\begin{array}{l}\text { Entering User SMS Phone } \\
\text { Number }\end{array}$ & Phone number is saved & Pass \\
\hline $\begin{array}{l}\text { Unable to Enter User } \\
\text { SMS Phone Number }\end{array}$ & $\begin{array}{l}\text { Phone number is not } \\
\text { saved }\end{array}$ & Pass \\
\hline $\begin{array}{ll}\text { Send User } & \text { SMS } \\
\text { Notification } & \\
\end{array}$ & $\begin{array}{l}\text { SMS Notification is } \\
\text { received }\end{array}$ & Pass \\
\hline $\begin{array}{l}\text { Unable To Send User } \\
\text { SMS Notification }\end{array}$ & $\begin{array}{l}\text { SMS Notification is not } \\
\text { received }\end{array}$ & Pass \\
\hline User Alarm Notification & Phone is ringed loudly & Pass \\
\hline $\begin{array}{ll}\text { Turn } \quad \text { Off } & \text { Alarm } \\
\text { Notification } & \end{array}$ & Phone is not ringed & Pass \\
\hline $\begin{array}{l}\text { Register Device } \text { With } \\
\text { ODM }\end{array}$ & $\begin{array}{l}\text { Device is registered and } \\
\text { is able to login }\end{array}$ & Pass \\
\hline $\begin{array}{l}\text { Unable To Register } \\
\text { Device With ODM }\end{array}$ & $\begin{array}{l}\text { Device is not registered } \\
\text { and fail to login }\end{array}$ & Pass \\
\hline Track Device With ODM & $\begin{array}{ll}\text { Device's } & \text { location } \\
\text { Tracked } & \\
\end{array}$ & Pass \\
\hline $\begin{array}{l}\text { Unable To Track Device } \\
\text { With ODM }\end{array}$ & $\begin{array}{l}\text { No information on } \\
\text { device }\end{array}$ & Pass \\
\hline $\begin{array}{l}\text { Lock the Phone with } \\
\text { ODM }\end{array}$ & $\begin{array}{l}\text { New password is saved } \\
\text { and the phone is locked }\end{array}$ & Pass \\
\hline
\end{tabular}

\section{CONCLUSION}

This project explores the possibility of preventing, detecting and securing a lost or misplace of an Android phone device efficiently. Android OS smartphone users are going to be the main targeted users for this application. This invention not only provides the prevention before losing phone, but provides also the solution after losing phone to the Android users. With the Bluetooth-enabled technology, the apps is able to trigger 
the loud alarm to alert the user before they forget or misplace the Android device. It will also send the SMS notification to the third party to notify the user, as well as for locking and tracking purposes. Security feature is another strength of the apps, which allows the user to remotely secure the misplaced device.

In summary, the app equips several unique features as its standing point. Such features are:

- SMS Notification using SmsManger Android library.

- Alarm Notification using MediaPlayer Android library.

- Locating and Tracking functions which are implemented with the open source ODM.

\section{Future Improvements}

This Missing Phone Prevention Alert Application can be improved in the future to achieve a bigger market area by making it compatibility to other smart phone operating system such as iOS devices. Besides that, the application can be upgraded to track and locate within the device without needing to set up a webhosting server. In addition, auto email notification can be used to replace the auto SMS notification.

\section{REFERENCES}

[1] A. Livingston. Smartphones and other Mobile Devices: the Swiss army knives of the $21^{\text {st }}$ Century. Educase Quarterly (EQ), 2004, 27(2).

[2] Skyrocketing demand for Bluetooth appcessories for latest phones.

Available: http://www.bluetooth.com/Pages/Mobile-TelephonyMarket.aspx (Accessed 5 January 2015).

[3] What is GPS? Available: http://www8.garmin.com/aboutGPS/ (Accessed 5 January 2015).

[4] Android still the dominant mobile OS with 1 billion active users.

Available: http://www.engadget.com/2014/06/25/google-io-2014-bythe-numbers/ (Accessed 5 January 2015).

[5] Plan B. Available: https://play.google.com/store/apps/details?id=com.lookou tlabs.planb\&hl=en (Accessed 5 January 2015).

[6] AntiDroidTheft. Available: https://play.google.com/store/apps/details?id=com.androi d.antidroidtheft\&feature (Accessed 5 January 2015).

[7] GadgetTrak. Available: https://itunes.apple.com/app/gadgettrak/id288927565?mt= 8 (Accessed 5 January 2015).

[8] FoneHome: https://itunes.apple.com/hk/app/fonehome-phonetrackerto/id378450421 ?mt=8 (Accessed 5 January 2015).

[9] Track Your Device Remotely with Open Device Manager. Available: http://www.xda-developers.com/android/trackyour-device-remotely-with-open-device-manager (Accessed 5 January 2015).

[10] GPS Phone Tracker Pro. Available: https://play.google.com/store/apps/details?id=com.fsp.and roid.c\&hl=en (Accessed 16 January 2015).
[11] Find My Android Phone!. Available: https://play.google.com/store/apps/details?id=com.fsp.and roid.phonetracker\&hl=en (Accessed 9 February 2015).

[12] Where's My Droid!. Available: https://play.google.com/store/apps/details?id=com.alienm anfc6.wheresmyandroid (Accessed 12 January 2015).

[13] SeekDroid. Available: https://play.google.com/store/apps/details?id=org.gtmedia .seekdroid\&hl=en (Accessed 12 January 2015).

\section{Authors' Profiles}

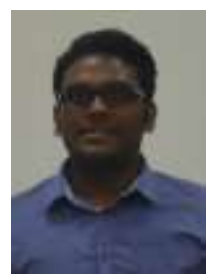

Kaven Raj Manoharan: received his bachelor degree from Faculty of Information Science \& Technology in Multimedia University majoring in Data Communication and Networking in 2015. He is actively involved in the projects of mobile application development.

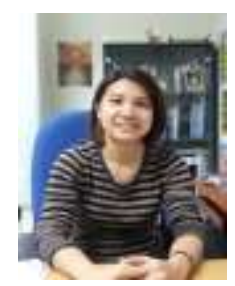

Siew-Chin Chong: received her bachelor's degree in Information Technology, majoring in Software Engineering and the Master degree in Science, majoring Information Technology from Multimedia University in 2003 and 2006 respectively. She is currently a $\mathrm{PhD}$ student of Faculty of Information Science \& Technology in Multimedia University. Her research interest includes mobile applications, wireless networking, pattern recognition and distance metrics learning.

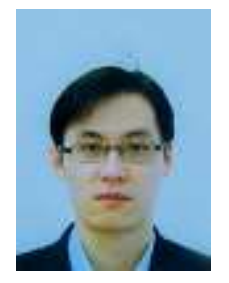

Kuok-Kwee Wee: received his BSc in Computer Science and MSc in Networking from University Putra, Kuala Lumpur, Malaysia. He then completed his study in $\mathrm{PhD}$ (Engineering) from Multimedia University, Malaysia. He is currently Senior Lecturer at the Faculty of Information Science and Technology in Multimedia University, Melaka, Malaysia. He is also a member of Editor Board of an International journal and Senior Member of IEEE. His research interests include Quality of service, broadband wireless access, networking and mobile communication.

How to cite this paper: Kaven Raj S/O Manoharan, Siew-Chin Chong, Kuok-Kwee Wee,"A Solution for Android Device Misplacement through Bluetooth-enabled Technology", International Journal of Intelligent Systems and Applications (IJISA), vol.7, no.11, pp.26-32, 2015. DOI: 10.5815/ijisa.2015.11.04 